\title{
Mesotherapy for Hair Loss-is it Useful? Review of Literature
}

\section{Deeptara Pathak Thapa, M.B.B.S, M.D, F.A.M}

Department of Dermatology, Nepal Medical College \& Teaching hospital, Gokarneshwar -7, Kathmandu, Nepal drdeeptarapathak@yahoo.com

*Corresponding Author: Dr. Deeptara Pathak Thapa, Assistant Professor, Nepal Medical College \& Teaching hospital, Gokarneshwar -7, Kathmandu, Nepal.

\section{Abstract}

Mesotherapy is defined as microinjection of pharmaceutical agents, amino acids and vitamins into the mesoderm. Mesotherapy for hair loss is commonly indicated for androgenic alopecia and tellogen effluvium. Mesotherapy is a well-advertised therapeutic modality on the internet and media but data on its safety and efficacy in cosmetic conditions are limited. In current situation no adequate, peer -reviewed clinical trials critically evaluating the efficacy of mesotherapy for dermatological and aesthetic indications are available. The mechanism of action of many of the products is either doubtful or unknown and there are no clear cut guidelines on the dosage and efficacy of the products.

Key words: Hair loss; Mesotherapy; Minoxidil.

\section{INTRODUCTION}

Globally hair loss is a common aesthetically and psychosocially distressing condition. ${ }^{1,2}$ An estimated 35 million men and 21 million females in United States suffer some form of hair loss and $65 \%$ of men have visible hair loss by age 60 and $40 \%$ of women suffer visible hair loss by age $40 .^{3}$ The most common cause of hair loss is Androgenic alopecia. The number of hair loss sufferers, world-wide, seeking professional treatment more than doubled from 361,077 to 811,363. Men are more likely than women to look into hair restoration surgery ( $20 \%$ vs. $12 \%) .{ }^{4}$ However more women seek methods of non-surgical hair restoration, up 31.8\%. There are variety of therapeutic non-surgical options for hair loss, of which Minoxidil and Finasteride are FDA approved for androgenic alopecia, others like Dutasteride, Mesotherpy, Microneedling, PRP, Nutritionol, Antioxidants and Light therapy have recently gained popularity in clinics and social media platforms (however they have been tried in small number of patients). Mesotherapy, a term derived from Greek word "meso" means middle and "therapia" meaning to treat medically. It was first coined by Dr Michel Pistor, a French physician in 1952. He founded French society of Mesotherapy in 1964. In 1987 French national academy of medicine officially acknowledge mesotherapy as speciality. Mesotherapy is defined as micro-injection of pharmaceutical agents, amino acids, vitamins and others into the mesoderm. Connective tissue and Dermis of skin are embryonically derived from mesoderm and hence its importance in mesotherapy. Regarding its popularity, about 16,000 US physicians use mesotherapy in their daily medical practice. Growth of number of mesotherapy-trained physician which is estimated at 300 per month, mushrooming of mesotherapy centers across the globe and the conduct of numerous international congresses all speak of its status. Indications for mesotherapy are hair loss commonly for Androgenic alopecia, Tellogen effluvium, cellulite, lipolysis and skin rejuvenation. Drugs and Ingredients used for mesotherapy of hair loss are Minoxidil, Dutasteride, PRP, Biotin, Dexenol, Acetyl tetrapeptide-3, Biochanin-A, nano peptides and cocktails. Materials used for mesotherapy can be classified as principle/ major ingredients (have evidence, FDA) and as complementary/minor ingredients claimed to have improve the condition. Cocktail or the mixture should contain at least two or three principal agents for it to be effective. Procedure for mesotherapy for hair loss needs hypodermic needles or mesogun, with depth of $0.5 \mathrm{~mm}-0.6 \mathrm{~mm}$, frequency of session be once a week for 4 weeks then monthly maintenance and volume per session of $5 \mathrm{cc}$ for entire scalp. There are various techniques like 
Mesotherapy for Hair Loss- is it Useful? Review of Literature

point by point where $0.02-0.05 \mathrm{ml}$ of Drug solution perpendicular to the skin (4mm deep, about $1-2 \mathrm{~cm}$ apart), Nappage technique involves more superficial ( $2 \mathrm{~mm}$ deep infiltration) given at $45^{\circ}$ angle, epidermic (1 $1 \mathrm{~mm}$ deep) and papule technique where injection of the drugs at the dermoepidermal junction, between $2 \mathrm{~mm}$ and $4 \mathrm{~mm}$ are given raising a small papule and it is used for wrinkles, alopecia and mesobotox. ${ }^{5}$ Contraindications are pregnancy, Insulin Dependent Diabetes Mellitus, history of stroke, thromboembolic phenomenon and patients on medications like aspirin, warfarin, heparin etc. Cost of the procedure depends on geographic region, number of microinjections and sessions involved and medical care provider. Table 1 shows cost of mesotherapy for hair loss in $\$$ in different parts of the world.

Table 1. Countries showing Cost of mesotherapy for hair-loss in US\$

\begin{tabular}{|c|c|}
\hline Country & cost in US\$ \\
\hline Malaysia & $500-970$ \\
\hline USA & $300-800$ \\
\hline Spain & $395-450$ \\
\hline UK & $280-300$ \\
\hline Turkey & $247-300$ \\
\hline UAE & $80-100$ \\
\hline India & $30-125$ \\
\hline
\end{tabular}

There are few studies showing efficacy of some ingredients in review of literature. A randomized control trial done by Azam et al found efficacy of topical minoxidil inferior to mesotherapy with Minoxidil for androgenic alopecia . ${ }^{6}$ There are various studies showing effectiveness of mesotherapy with dutasteride. ${ }^{7,8,9,10}$ Promising result was seen with multivitamins and cocktails in french studies. ${ }^{11,12}$ Biocanin -A which is derived from red clover is a natural phytochemical flavonoids traditionally used for cancer, asthma and inflammatory disorders has now gained its popularity in hair loss treatment due to its proposed mechanism of modulation of conversion of testosterone to DHT. ${ }^{13}$ Acetyl tetra peptide- 3 is also a new molecular compound which has several properties like to decrease inflammatory response, modulates levels of DHT, stimulates the extracellular matrix and anchoring proteins and stimulates tissue remodeling and thus helps in treatment of hair loss.
Both the compounds have gained popularity in private clinics but as such well controlled trials are not available in the literature. One of my personal experience (as shown in Figure-1) in a patient of alopecia areata, right side of the scalp was treated with Intralesional steroid injections with triamcinolone acetonide and left side mesotherapy with cocktail containing nicotinic acid, pantheon, zinc, Vitamin B6 etc. After four sessions, hair growth was more in right side treated with intralesional steroid as compared to left side with mesotherapy cocktail (moderate hair growth could be seen).
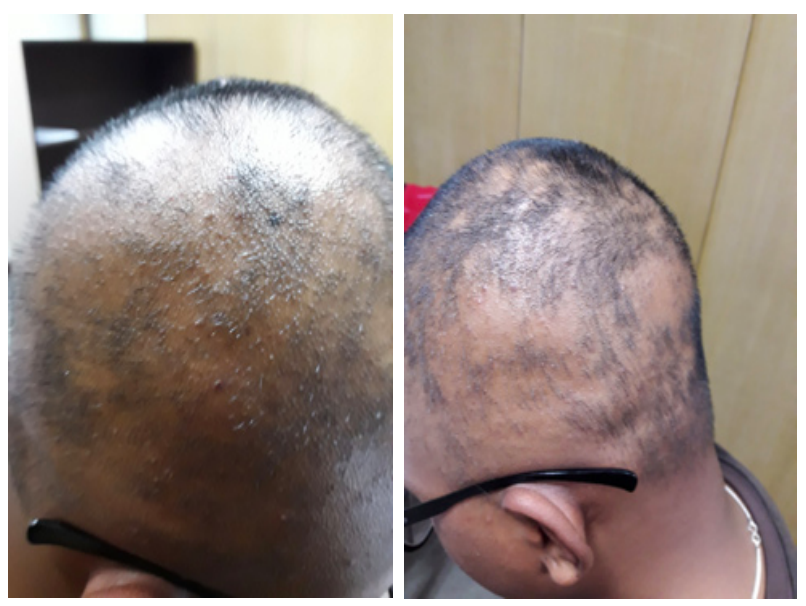

Befor treatment $\mathrm{a}, \mathrm{b}$

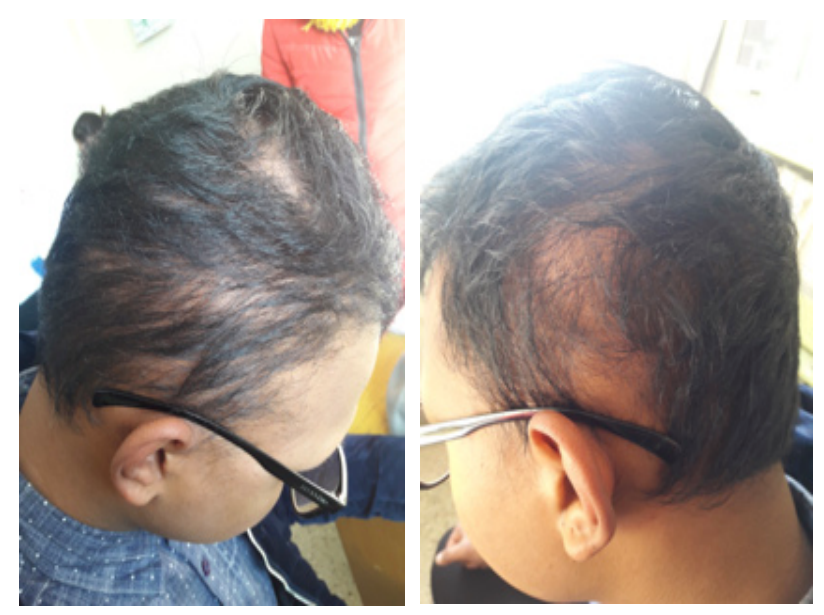

After treatment ocktail c, d

Figure 1. Photographs showing compassion of both right side (intralesional steroid) and left side before treatment and after treatment(cocktail)Pasted Graphic $a, b, c, d$.

In contrast to the claims of mesotherapy being a safe minimally invasive procedure several side effects have been reported. It is also interesting to note that 
Mesotherapy for Hair Loss- is it Useful? Review of Literature

in contrast to lack of data on its efficacy, there are a number of published studies about its' complications. Adverse effect with mesotherpy for hair loss are few but as quoted in the literature are multifocal scalp abscess, scalp melanoma, and contradictory hair loss at injection sites. ${ }^{14,15,16,17}$ There are other local side effects like bruising, skin necrosis, atypical mycobacteria, allergic reaction, lichenoid reaction, post inflammatory hyper pigmentation, infections which have been noticed after mesotherapy for lipolysis ${ }^{18,19,20,21,22}$. Mesotherapy is a well- advertised therapeutic modality on the internet and media and is practiced in Europe and South America, data on its safety and efficacy in cosmetic conditions are limited.

Currently there are no adequate, peer-reviewed clinical trials critically evaluating the efficacy of mesotherapy for dermatological and aesthetic indications. Proper controlled data and more evidences are needed before any recommendations. There are insufficient data evaluating the safety of the technique and pharmacology of the combination of herbal and allopathic medicines. The mechanism of action of many of the products is either doubtful or unknown and there are no clear guidelines on the dosage and efficacy of the products. Despite the boom in mesotherapy in the west, mesotherapy is a controversial therapy at the moment and it is still in its infancy. The CDC has recommended that "providers should adhere to recommend standard precautions, follow safe-injection practices with appropriateaseptic techniques and inject only FDA approved products that are prepared following guidelines to ensure sterility described in the FDA's good manufacturing practices" $^{18,23}$.

\section{ConClusion}

Till now there are no well controlled studies to prove the efficacy of this treatment modality. It is not approved by the FDA and scientific data to support its efficacy is lacking. No clear guidelines on the dosage and efficacy of these products exist. Additional clinical and experimental studies are necessary to establish the safety and efficacy of this treatment. More controlled and published studies in the literature are still awaited for the dermatologists to decide the future of this technique in their practice. Until such time the use of this technique will probably remain a subject of controversy.

\section{REFERENCES}

[1] Springer K, Brown M, Stulberg DL. Common hair loss disorders. Am Fam Physician. 2003;68:93102.

[2] Krupa Shankar DS, Chakravarthi M and Shilpakar R. Male androgenic alopecia: Population -Based study in 1005 subjects. Int J Trichology.2009;1(2): 131-133

[3] https:thehairsociety.org/hairloss-statisticsthefacts/

[4] https://www.belgraviacentre.com/bolg/hairloss-facts-figures-and-statistics

[5] Konda D, Thapa DM. Mesotherapy: what is new? . Indian J Dermatol Venerol 2013;79:127-34

[6] Azam H, Morsi HM. Egyptiaan dermatology online journal 2010;6(2):5

[7] Corallo . Int J Trichology 2017;9(3):143-145

[8] Eun HC,Kwon OS,Yeon JH, Shin HS, Kim BY, Ro BI et al. Efficacy, safety and tolerability of dutasteride $0.5 \mathrm{mg}$ once daily in male patients with male pattern hair loss:A randomized double blind, placebo controlled, phase III study. J Am Acad Dermatol 2010; 63:252-8

[9] Moftah N, Abd-Elaziz G, Ahmed N,Hamed Y, Ghannam B et al. J Eur Acad Dermatol Venerol,2013;27:686-93

[10] Sobhy. Our Dermatology Online.2013;4:40-5

[11] Duchkova M, Haskova M. Cas Lek Ces.2015;154(2):90-4

[12] Ihrisky SA. Cas Lek Ces. 2017 ;156(3):145-146

[13] Hiipakka. Biochem Pharmacol.2002;63(6):116576

[14] El- homy M, Hassan A, Tawdy A,Solimon M, Hadi MA. Hair loss at injection sites of Mesotherapy for Alopecia.J Cosmet Dermatol.2017; 16(4):e28-e30

[15] Duque- Estrada B, Vincenzi C, Misciali C,Tosti A. alopecia secondary to mesotherapy.J Am Acad Dermatol.2009;61(4):707-

[16] Kadry R, Hamadah, Al-Issa A, Field L, Alrabiah F. Multifocal scalp abscess with subcutaneous fat 
Mesotherapy for Hair Loss- is it Useful? Review of Literature

necrosis and scaring alopecia as a complication of scalp mesotherapy. J Drugs Dermatol 2008;7(1);72-3

[17] Arenbergerova M, Arenberger P, Gkalpakiotis S, Dahmen RA, Sticova E, Fialova A.Scalp melanoma after antihair loss mesotherapy .J Eur Acad Dermatol Venereol 2018;32(5):e187-e188.

[18] Vedamurthy M. Mesotherapy. Indian J Dermatol Venereol leprol 2007;73:60-2

[19] Lee DP. Sucutaneous nodules showing fat necrosis owing to mesotherapy.Dermatol Surg $2005 ; 31: 250-1$
[20] Herreros Fernanda OC, Moraes AM, Velho Paulo ENV. Mesotherapy a bibliographical reveiw.An Bras Dermatol 2011;86(1)

[21] Sivagnanam G. Mesotherapy-The French connection.Int J Drmatol 2007;46:649-53

[22] Rotunda AM, Kolodney MS. Mesotherapy and Phosphatidylcholine Injections: Historical clarification and Reveiw.Ann Med Interne 1995; 146:365-6

[23] Sarkar R,Garg VK, Mysore V.Position paper on mesotherapy. Indian J Dermatol venereol Leprol 2011;77(2);232-37

Citation: Dr. Deeptara Pathak Thapa. Mesotherapy for Hair Loss- is it Useful? Review of Literature. Archives of Dermatology and Skin Care. 2018; 1(1): 7-10.

Copyright: (C) 2018 Dr. Deeptara Pathak Thapa. This is an open access article distributed under the Creative Commons Attribution License, which permits unrestricted use, distribution, and reproduction in any medium, provided the original work is properly cited. 